\title{
Estudo dos anéis de crescimento da araucaria angustifolia (bertol.) Kuntze no município de Tapera - RS
}

Study of the growth rings in the araucaria angustifolia (bertol.) Kuntze in Tapera city - RS

\author{
Aldiara Fernanda Pavão Garcia', Roselaine Ruviaro Zanini"
}

\begin{abstract}
RESUMO
O presente trabalho teve como objetivo analisar o crescimento das espessuras dos anéis de crescimento de árvores da Araucaria angustifolia, presentes no município de Tapera, Rio Grande do Sul. Nesta pesquisa, foram utilizadas 44 amostras da Araucaria angustifolia, analisadas nas últimas seis décadas, para encontrar uma equação, por meio de modelos de regressão que descrevessem o desenvolvimento dos anéis de crescimento das árvores. Assim, realizou-se uma análise descritiva das medidas coletadas (espessura dos anéis), para onze árvores, por década, considerando-se o período entre 1950 a 2009, apresentando-se os valores da média, mediana, mínimo, máximo, desvio-padrão e coeficiente de variação, para caracterizar a amostra estudada. Posteriormente, realizou-se uma análise de regressão, por quinquênio, na qual se procurou, entre os vários tipos de modelos disponíveis, como o modelo Linear, Cúbica, Inversa e Compound, aquele que melhor estimasse a espessura dos anéis médios das árvores analisadas. O melhor modelo que se ajustou aos dados foi o Compound, do qual não se encontrou material disponível que viesse a detalhar este tipo de modelo encontrado. Dessa forma, analisou-se que a espessura dos anéis total (lenhos de início e fim de estação) dos anéis de crescimento para cada uma das onze amostras de árvores, as quais cresceram e decresceram ao longo das últimas décadas. Essa variação pode ser explicada pelos fatores ambientais que agiram neste quinquênio e resultaram na formação da espessura dos anéis.
\end{abstract}

Palavras-chave: Crescimento de árvores. Evolução Temporal. Análise de regressão

\begin{abstract}
This study had as objective to analyze the growth of thickness of growth rings of trees of Araucaria angustifolia, present in Tapera city, Rio Grande do Sul. In this study, it was used 44 Araucaria angustifolia samples, analyzed in the past six decades, to find an equation, using regression models that describe the development of the growth rings of trees. Thus, it was done a descriptive analysis of the collected measurements (thickness of the rings), for the eleven trees, per a decade, considering the period from 1950 to 2009, presenting the average values, median, minimum, maximum, standard deviation and coefficient of variation, to characterize the analyzed sample. After, it was performed a regression analysis, for five years, in which it was searched, among the various types of models available that, the linear, cubic, inverse and compound, one that best estimated the thickness of the average tree ring analyzed. The best model which fit to the data was the Compound, which was not found available material that detailed this type of found model. This way, it was considered that the thickness of the full rings (beginning logs and end of season) the growth rings to each of the eleven samples of trees, which ones have grown and declined over the past decades. This variation can be explained by environmental factors that acted in this five-year period and resulted in the formation of the thickness of the rings.
\end{abstract}

Keywords: Tree growth. Time evolution. Regression analysis 


\section{INTRODUÇÃO}

As árvores revelam informações sobre o ambiente devido ao fato de suas propriedades armazenarem informações da sua formação. Tais atributos, como a densidade e a largura dos anéis, são fatores importantes para os estudos dendrocronológicos, baseados em correlações de fenômenos climáticos e ambientais. Dessa forma, tem sido amplo o desenvolvimento na ciência com trabalhos que trazem as pesquisas baseadas no estudo dos anéis de crescimento. Nesse contexto, vários testes nas amostras com as espessuras dos anéis de crescimento podem ser realizados, a fim de analisar a relação de parâmetros como a precipitação pluviométrica e temperatura. Nesse sentido, fenômenos naturais tais como SOI (Índice de Oscilação Sul- El Niño e La Niña) e ciclo solar, são observados para entender a conexão com o desenvolvimento da espessura dos anéis de crescimento das árvores da espécie Araucaria angustifolia, típica da região Sul.

A dendrocronologia é uma ciência que analisa e interpreta o crescimento das árvores através do estudo de seus anéis de crescimento. O termo, que provém do grego dendron ou árvore, kronos ou tempo, e logos ou conhecimento, representa um dos métodos científicos mais utilizados nas datações aplicadas a madeiras (GONÇALVES, 2007-2008). Em outras palavras, dendrocronologia é um conjunto de métodos que tem como objetivo principal a identificação dos anéis de crescimento anual das árvores e a alocação de cada um, de forma precisa e inequívoca, há um ano concreto no calendário gregoriano, em que o último ano corresponde ao ano de recolha da amostra (LAUW, 2011).

$\mathrm{Na}$ dendroclimatologia, os registros climáticos se acumulam nos anéis sob a forma da sua espessura, densidade, compostos, etc, e são utilizados para reconstruir climas e fatores ambientais presentes no passado. Desse modo, trabalhos de dendrocronologia permitem analisar as alterações e evoluções de paisagens de determinadas localidades, bem como trabalhos realizados no Alto de S. Bento, em Évora. Este estudo apresenta uma abordagem relacionada ao incremento dos anéis de crescimento da Araucaria angustifolia no município de Tapera - RS. A região Sul do Brasil vem passando por um período climático atípico, em que se faz necessário o estudo de 
algumas décadas passadas para saber como estes fenômenos agiam. Dessa maneira, através de uma análise dendrocronológica da espécie Araucaria angustifolia da localidade do município de Tapera, RS, procurou-se modelos de regressão que descrevessem o desenvolvimento das espessuras dos anéis de crescimento. Os vários fatores climáticos são os responsáveis pela alteração da espessura dos anéis de crescimento. A Araucaria angustifolia, por ser uma espécie sensível às variações ambientais, permite que alterações do clima, como temperatura, precipitação, umidade, radiações solares, eventos de El Niño e La Niña, e de outros fenômenos físicos e geofísicos, como a atividade solar, cosmonuclideos atmosféricos, entre outros, fiquem registradas nos seus anéis de crescimento.

Os registros destes fenômenos nos anéis de crescimento, também foram documentados por Rigozo et al. (2008) e Prestes (2006) em seus estudos. Inúmeras são as informações contidas nos anéis de crescimento, além da identificação e reconstrução das condições climáticas do passado, é possível conhecer as alterações ambientais naturais, avaliar o efeito dos ventos, a ocorrência de ataques de insetos e microrganismos, os processos tectônicos, as atividades vulcânicas, os incêndios, as operações silviculturais, a presença de metais pesados no ambiente e de ações antropogênicas (BOTOSSO e MATTOS, 2002). A Araucaria angustifolia é espécie característica e exclusiva da Floresta Ombrófila Mista (Floresta com Araucária), nas formações Aluviais, a espécie é também encontrada nas áreas de tensão ecológica, com a Floresta Estacional Semidecidual e com a Floresta Ombrófila Densa (Floresta Atlântica). Em regiões caracterizadas por clima temperado, os anéis de crescimento representam o incremento anual da árvore. A cada ano é acrescentado um novo anel ao tronco, sendo também chamados de anéis anuais, cuja contagem permite conhecer a idade do indivíduo (BURGER e RICHTER, 1991). Em um anel de crescimento típico distinguem-se normalmente duas partes: a do lenho inicial (lenho primaveril) e a do lenho tardio (lenho outonal ou estival). Portanto, o presente trabalho tem por objetivo responder ao seguinte questionamento: qual o comportamento dos incrementos dos anéis de crescimento de araucárias nas últimas seis décadas e qual o modelo de regressão apropriado para descrevê-lo no município de Tapera no RS? 


\section{MATERIAIS E MÉTODOS}

O presente trabalho caracteriza-se como uma pesquisa explicativa, visando identificar os fatores que determinam ou contribuem para a ocorrência dos fenômenos, aprofunda o conhecimento da realidade. Requer o uso do método experimental e observacional, a qual envolve levantamento experimental e expost-facto (Gil, 2009, p.42). Em outros termos, pode-se dizer que a pesquisa explicativa tem como preocupação central identificar os fatores que determinam ou que contribuem para a ocorrência dos fenômenos. Nesse sentido, pode-se dizer que o conhecimento científico está assentado nos resultados oferecidos pelos estudos explicativos.

A pesquisa experimental e a expost-facto, tem o mesmo propósito: verificar a existência de relação entre variáveis. O que difere uma da outra é o fato em que, na expost-facto, o pesquisador não dispõe de controle sobre a variável independente, que constitui o fator presumível do fenômeno, porque já ocorreu. O que o pesquisador procura fazer neste tipo de pesquisa é identificar situações que se desenvolveram naturalmente e trabalhar sobre elas como se estivessem submetidas a controles (GIL, 2009).

Primeiramente fez-se um estudo bibliográfico, em artigos científicos, dos temas analisados no trabalho, visando destacar a importância da Dendrocronologia, da Araucária, dos anéis de crescimento e da Climatologia, em relação à localidade da qual as amostras para o estudo foram coletadas. Logo, a pesquisa caracterizou-se como explicativa e expost-facto, visando um entendimento mais abrangente dos temas abordados no estudo. Na segunda etapa, já analisados os temas e obtidas as cronologias dos anéis de crescimento da localidade explorada, deu-se início ao processo de interpretação dos dados.

\subsection{Caracterização do local de coleta}

As amostras analisadas foram coletadas no município de Tapera (RS), localizado (28 S, 52 O, alt. 409 m), caracterizado por apresentar Floresta Ombrófila Mista, em que, de acordo com a classificação de Köppen (MORENO, 1961), a região apresenta clima do tipo "Cfa", por apresentar chuvas bem distribuídas regularmente em todos os meses do ano, ou seja, um clima subtropical. A temperatura média anual varia de 12,70 
C a $17,5^{\circ}$ C. Possui precipitação média anual de 1664 mm. Em janeiro de 2010, em um trabalho de campo financiado pela FAPESP e INPE juntamente com os pesquisadores Dr. Alan Prestes (UNIVAP), Adelton Prestes (UFSM/INPE) e Pabulo Rampelotto (UFSM), as 44 amostras do município de Tapera (RS), foram coletadas nas proximidades das coordenadas: latitude de -28.689731 e longitude de -52.856149 . Armazenadas e analisadas no Laboratório de Registros Naturais Relação Sol -Terra - Clima do CRS/INPE.

\subsection{Material e amostragem}

A espécie das onze árvores amostradas, em 2010, foi escolhida em função de apresentar anéis de crescimento anuais bem definidos e por ser uma espécie longeva, ou seja, de crescimento lento. A Araucaria angustifolia, conhecida popularmente como pinheiro ou pinheiro do Paraná, é uma espécie característica e exclusiva da Floresta Ombrófila Mista. Ela forma anéis de crescimento anuais com nítidos lenhos inicial e tardio, identificados macroscopicamente, no xilema, o que permite a determinação da idade da árvore. É uma árvore de aspecto original e contrastante com as demais árvores do Sul do Brasil, com $10 \mathrm{~m}$ a $35 \mathrm{~m}$ de altura e 50 a $120 \mathrm{~cm}$ de DAP (diâmetro à altura do peito, medido a 1,30 m do solo), atingindo $50 \mathrm{~m}$ de altura e $250 \mathrm{~cm}$ ou mais de DAP na idade adulta (CARVALHO, 2003).

O método de coleta foi o não destrutivo, no qual com o auxílio de um Trado ou Sonda de Pressler à altura do peito $(1,30 \mathrm{~m})$, retira-se quatro cilindros (baguetas ou rolo de incremento) de madeira de cada árvore, de modo que se obtenha uma representação de todos os anéis de crescimento formados desde a casca até a medula, sem que o método ocasione danos à mesma. Dessa forma, este método de extração permite que seja possível retirar várias amostras de uma árvore em pé, sem a necessidade de derrubá-las e ajudando na preservação da espécie. Foram coletas 48 amostras não destrutiva, sendo retirados 4 rolos de incremento (ou bagueta) de cada árvore, das 12 árvores coletadas. Logo após, a retirada da amostra da árvore, esta libera uma quantidade de água retida no seu interior, mas, que não causa dano na sua estrutura. Este orifício aberto é fechado com serragem de árvores do mesmo local de coleta, porém, derrubadas por alguma influência do tempo. A amostra da medula à 
casca pronta para ser acondicionada no canudinho. Ainda no campo de estudo, as amostras foram armazenadas em canudinhos cilíndricos de plástico e etiquetadas com um código identificativo pela ordem da coleta (como por exemplo, TP 1C, que significa Tapera Árvore 1 Raio C). As quatro amostras de cada árvore, que representam os raios das mesmas, foram denominadas com as letras A, B, C e D.

Após, a coleta, as amostras foram preparadas no Laboratório de Análise Digital de Dados do INPE/CRS, foram preparadas as caneletas de madeira ou suporte com a identificação para armazenar cada rolo de incremento ou bagueta da amostra de respectiva árvore. As caneletas de madeira ou suportes apresentam um entalhe em todo seu comprimento para poder fixar o rolo de incremento ou bagueta da amostra. Como identificações são usadas as iniciais da cidade de coleta da amostra e o número da árvore coletada juntamente com o número de identificação para cada um dos quatro raios, em seguida, em todo o entalhe foi adicionada cola constituída de poliacetato de vinila (PVA) à base de água para não corroer a amostra.

As amostras foram fixadas, levemente, nos entalhes para não danificar a amostra e com a disposição dos anéis voltados para cima para facilitar as marcações após a lixagem. Cada caneleta de madeira ou suporte já com a amostra fixada foi envolvida com barbante para ficar mais resistente, sendo que a secagem das amostras deve ser em temperatura ambiente para evitar o empenamento do rolo de incremento e evitar problemas como a quebra da amostra, e as amostras prontas para serem lixadas e depois analisadas. Após a secagem das caneletas de madeira, as amostras foram polidas com uma sequência decrescente de lixas com diferentes granulações, tais como: 80, 120, 180, 220, 320 e 400 granas. Uma lixadeira orbital manual, também foi utilizada no processo de preparação da amostra para tornar a superfície plana, lisa e visível, destacando assim as características anatômicas da amostra. Após serem lixadas, as caneletas de madeira foram polidas de modo a tornar os anéis de crescimento mais visíveis e facilitar a contagem e correspondente medição. Em amostras onde os anéis de crescimento não são nítidos, podem-se utilizar produtos químicos (fuccina, azul de metileno, álcool, etc.) para melhorar a visualização dos mesmos. 


\subsection{Análise da mensuração das amostras}

As onze amostras representam cada árvore, e cada cilindro (rolo de incremento ou bagueta) um conjunto de quatro raios que formam uma árvore em estudo. Após o processo de lixação, as amostras de cada árvore foram sincronizadas antes de serem analisadas no estéreo-microscópio. Essa sincronização consiste em analisar se as séries estão sobrepostas e visualmente comparadas entre si, com o objetivo de verificar as medições das séries de anéis de crescimento, e também confirmar e corrigir a presença de falsos anéis ou ausência de anéis (LAUW, 2011). Não havendo uma boa sincronização entre as amostras da mesma árvore, estas são rejeitadas e não são incluidas na análise dos resultados. No presente estudo, a amostra da árvore TP 2, foi rejeitada por suas amostras de cada espessura do raio, não estarem sincronizadas e por também apresentar apenas três dos raios coletados, sendo que das outras amostras das árvores foram analisados quatro raios de cada árvore. Logo após a sincronização, em uma mesa de digitação Velmex, com um estéreo-microscópio, a mensuração das amostras foram realizadas e lançadas no programa MEASURE J 2X (Tree Ring Measuring Program), permitindo que as séries com as espessuras dos anéis de crescimento, em milímetros, fossem geradas e analisados seus gráficos no Microsoft Excel, obtendo-se assim a relação entre a espessura ( $\mathrm{mm}$ ) e o tempo (anos).

No estéreo-microscópio, as amostras foram analisadas no sentido da medula para a casca, ou seja, a medula é o ponto zero para verificar a dimensão acumulada dos anéis de crescimento, observando-se os lenhos iniciais e tardios, como também delimitadando-as em milimetros. Dessa forma, a contagem dos anéis de crescimento foi realizada em todas as caneletas de madeira de cada árvore. A mensuração foi repetida toda vez que se detectava alguma confusão ou falha, até que se visualizasse a série representativa da amostra. Após a mensuração das amostras lançadas no programa MEASURE J 2X (Tree Ring Measuring Program) permitindo a visualização das séries com as espessuras dos anéis de crescimento em mm (milímetro), na Figura 1, gerou-se as séries das espessuras ( $\mathrm{mm}$ ) versus tempo (anos), através de seus gráficos no Microsoft Excel para cada um dos raios de cada árvore, obtendo-se assim a relação entre a espessura ( $\mathrm{mm}$ ) e o tempo (anos). 
Figura 1 - Cronologia das amostras da árvore que representa TP 5.

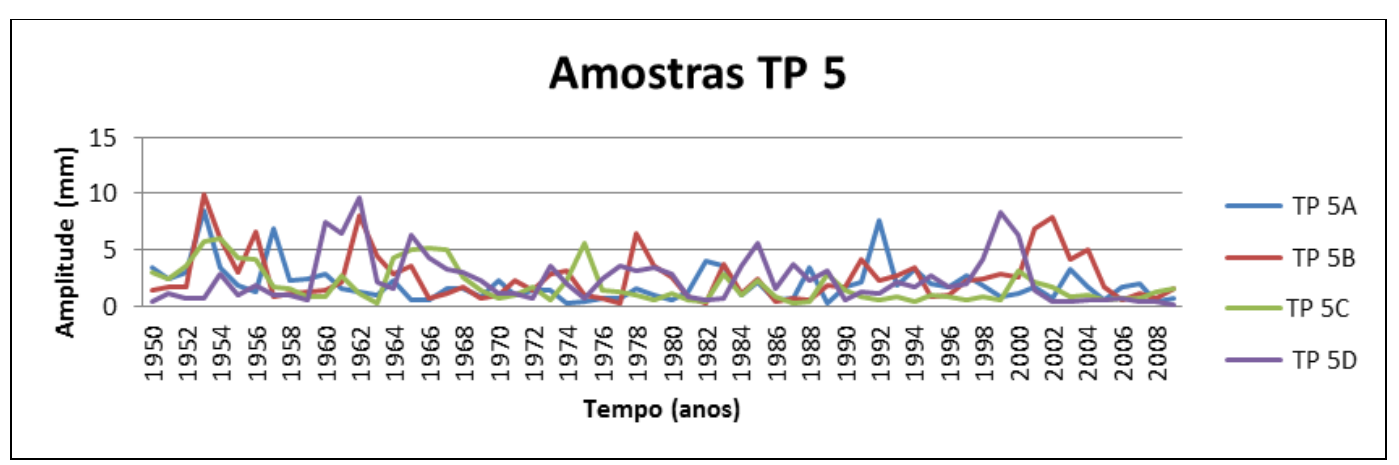

As séries apresentam uma sincronização extremamente paralela em relação às outras amostras representativas das outras séries. Através das quatro espessuras dos raios da amostra TP 5 da Figura 1, fez-se a média aritmética para estimar a espessura dos anéis de crescimento de forma mais representativa conforme a Figura 2, representando assim a cronologia média da árvore TP 5.

Figura 2 - Média da cronologia de TP 5.

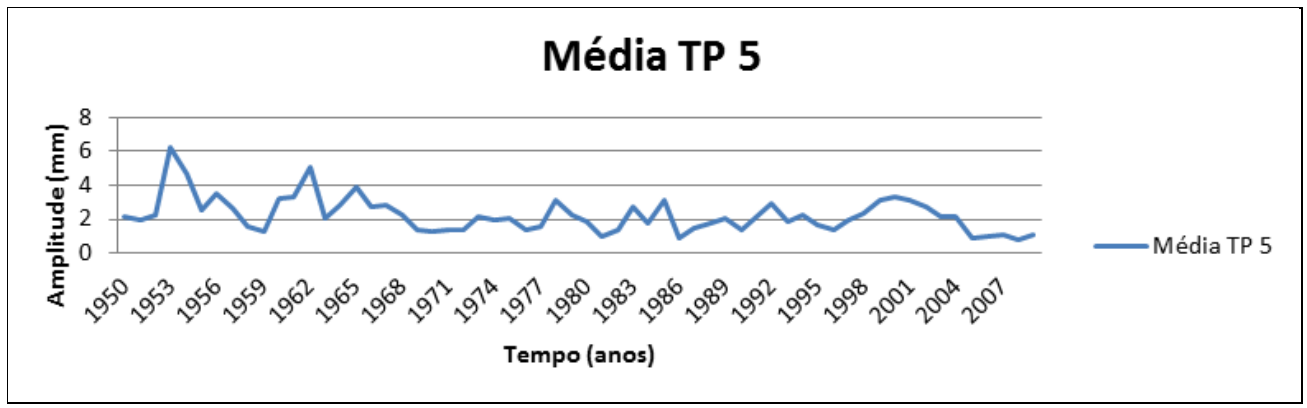

Assim, neste estudo realizou-se uma análise descritiva das medidas coletadas (espessura dos anéis de crescimento dos raios), para as onze árvores, por década, considerando-se o período entre 1950 a 2009, apresentando-se os valores da média, mediana, mínimo, máximo, desvio-padrão e coeficiente de variação, para caracterizar a amostra estudada.

Posteriormente, procedeu-se a análise de regressão, por quinquênio, onde se procurou, entre os vários tipos de modelos disponíveis, aquele que melhor representasse as espessuras dos anéis de crescimento dos raios médios das árvores analisadas. Para as análises estatísticas foram utilizados o PAWS 18.0 e os testes dos coeficientes dos modelos foram realizados considerando-se 5\% de significância. 


\subsection{Regressão linear simples}

A análise de regressão é uma das técnicas estatísticas mais utilizadas para investigar e modelar o relacionamento existente entre as diversas variáveis de um processo. Essa técnica é baseada na ideia relativamente simples de se empregar uma equação para expressar o relacionamento entre as variáveis de interesse (WERKEMA E AGUIAR, 1996). Dessa forma, a partir do uso desta equação, a identificação dos fatores que estão agindo sobre os resultados de um processo e a determinação do foco de um problema ficam mais perceptíveis, sendo possível a realização de previsões (JACOBI, SOUZA E PEREIRA, 2002).

\subsection{Coeficiente de correlação de Pearson}

O coeficiente de correlação é uma medida da força e direção de uma relação linear entre duas variáveis, conhecido como coeficiente de correlação produtomomento de Pearson em homenagem ao estatístico inglês Karl Pearson (1857-1936) que o introduziu. (FONSECA, MARTINS e TOLEDO, 1985).

Simbolicamente, $r$ pode ser denotado como:

$$
r_{x y}=\frac{\sum x y-\frac{\left(\sum x\right)\left(\sum y\right)}{n}}{\sqrt{\left[\sum x^{2}-\frac{(\Sigma x)^{2}}{n}\right]} \sqrt{\left[\sum y^{2}-\frac{\left(\sum y\right)^{2}}{n}\right]}}=\frac{s_{x y}}{\sqrt{S_{x x}} \sqrt{S_{y y}}}
$$

Onde:

x e y = variáveis do estudo

$\mathrm{n}=$ número de pares de dados presentes

$\sum \mathrm{x}=$ soma dos valores de $\mathrm{x}$

$\sum \mathrm{y}=$ soma dos valores de $\mathrm{y}$

$\sum \mathrm{xy}=$ Soma do produto de cada valor $\mathrm{x}$ por seu correspondente $\mathrm{y}$

$\sum \mathrm{x}^{2}=$ Soma do quadrado de cada valor de $\mathrm{x}$

$\sum \mathrm{y}^{2}=$ Soma do quadrado de cada valor $\mathrm{y}$

$\mathrm{S}_{\mathrm{xy}}=$ Covariância de $\mathrm{x}$ e $\mathrm{y}$

$\mathrm{S}_{\mathrm{xx}}=$ Variância de $\mathrm{x}$

$\mathrm{S}_{\mathrm{yy}}=$ Variância de $\mathrm{y}$ 
A significância do coeficiente de correlação pode ser verificada por meio de um teste de hipóteses.

\subsection{O Método dos Mínimos Quadrados (MMQ)}

Na regressão linear deve-se encontrar a equação da linha de regressão, que represente o relacionamento linear entre as duas variáveis consideradas.

Esse relacionamento pode ser representado por uma equação em que os parâmetros $\beta_{0}$ e $\beta_{1}$, representam o intercepto e a inclinação da reta. Usualmente X é denominada a variável independente, explicativa, regressora ou preditora, sendo Y a variável dependente ou resposta. A equação (2) que também é denominada o modelo de regressão linear simples, é representada por:

$$
\hat{y}=\beta_{0}+\beta_{1} x+\varepsilon
$$

Em que $\varepsilon$ é um resíduo ou erro aleatório com média zero, variância $\sigma^{2} \mathrm{e}$ distribuição normal. Sendo os parâmetros $\beta_{0}$ e $\beta_{1}$ desconhecidos, é necessário estimálos por meio do emprego de dados amostrais. Esse critério para estimar os parâmetros de regressão é chamado de método dos mínimos quadrados, o qual consiste em adotar como estimativa dos parâmetros os valores que minimizem a soma dos quadrados dos desvios.

O método dos mínimos quadrados ordinários é atribuído a Carl Friedrich Gauss, um matemático alemão. O método dos mínimos quadrados tem algumas propriedades estatísticas muito atraentes, que fizeram dele um dos mais poderosos e populares métodos de análise de regressão (GUJARATI, 2000).

A existência de regressão linear pode ser verificada pela análise da significância do coeficiente de regressão $\beta$.

No Quadro 1 de análise de variância ou tabela ANOVA, descrita abaixo, tem-se as quantidades necessárias para calcular o valor observado da estatística do teste. 
Quadro 1 - Análise de variância para testar a significância da regressão (ANOVA).

\begin{tabular}{|l|c|c|c|c|}
\hline $\begin{array}{l}\text { Causas } \\
\text { de Variação }\end{array}$ & $\begin{array}{c}\mathrm{GL} \\
\text { (Graus de Liberdade) }\end{array}$ & $\begin{array}{c}\mathrm{SQ} \\
\text { (Soma de Quadrados) }\end{array}$ & $\begin{array}{c}\mathrm{QM} \\
\text { (Quadrado Médio) }\end{array}$ & $\mathrm{F}_{0}$ \\
\hline Regressão & 1 & $\mathrm{SQR}$ & $\mathrm{SQR}$ & $\frac{\mathrm{SQR}}{\mathrm{SQE} /(\mathrm{n}-2)}$ \\
\hline $\begin{array}{l}\text { Erro } \\
\text { ou Resíduo }\end{array}$ & $\mathrm{n}-2$ & $\mathrm{SQE}$ & $\mathrm{SQE} /(\mathrm{n}-2)$ & \\
\hline Total & $\mathrm{n}-1$ & $\mathrm{SQT}$ & & \\
\hline
\end{tabular}

\subsection{Coeficiente de Determinação ou de Explicação $\left(\mathbf{R}^{2}\right)$}

O coeficiente de determinação indica quantos por cento a variação explicada pela regressão representa da variação total. Dessa forma, em (3) tem-se:

$0 \leq \mathrm{R}^{2} \leq 1$

Logo em (4), o coeficiente de determinação pode ser definido por:

$$
\mathrm{R}^{2}=\frac{\mathrm{VE}}{\mathrm{VT}}=\frac{\mathrm{b}^{2} \cdot \mathrm{S}_{\mathrm{xx}}}{\mathrm{S}_{\mathrm{yy}}}=\frac{\mathrm{SQR}}{\mathrm{SQT}}
$$

Em (4), essa relação mostra que a variação dos valores de $Y$ em torno de sua média pode ser dividida em variação explicada pela regressão (VE) e variação não explicada pela regressão ou variação residual (VR), onde nem todos os pontos estão sobre a reta da regressão e VT, representa a variação total. Assim em (5) temos:

$$
\mathrm{SQT}=\mathrm{SQR}+\mathrm{SQR} \text { resíduo }
$$

A Soma dos Quadrados Total (SQT) caracteriza-se pela dispersão da variação aleatória Y que se mede por meio da soma dos quadrados dos desvios em relação a sua média Y. Assim, tem-se em (6):

$$
\mathrm{SQT}=\sum\left(\mathrm{Y}_{\mathrm{i}}-\bar{Y}\right)^{2}
$$

\subsection{Regressão não linear}

Na regressão não linear, os coeficientes da equação encontram-se na forma de produto ou fracionária e elevados à expoente não unitário. Como exemplo, podem-se citar as equações encontradas e que descrevem o desenvolvimento dos modelos conforme em (7), (8) e (9): 


$$
\begin{array}{ll}
\widehat{\mathrm{Y}}=\mathrm{b}_{0} \cdot \mathrm{b}_{1}{ }^{\mathrm{t}} & \text { (Compound) } \\
\widehat{\mathrm{Y}}=\mathrm{b}_{0}+\mathrm{b}_{1} \mathrm{t}+\mathrm{b}_{2} \mathrm{t}^{2}+\mathrm{b}_{3} \mathrm{t}^{3} & \text { (Cúbica) } \\
\widehat{\mathrm{Y}}=\mathrm{b}_{0}+\left(\frac{\mathrm{b}_{1}}{\mathrm{t}}\right) & \text { (Inversa) }
\end{array}
$$

Os modelos não lineares nos parâmetros podem ser estimados por mínimos quadrados, mas exigem algoritmos numéricos para obter estimativas que minimizem a função de mínimos quadrados, assim como os modelos não lineares nas variáveis, pode ser analisado com o auxílio da regressão de mínimos quadrados, desde que as hipóteses usuais sobre regressão sejam verificadas (HILL, GRIFFITHS e JUDGE, 2006). No modelo de regressão linear as variáveis $X$ e $Y$ podem ser transformações que envolvem logaritmos, quadrados, cubos ou inversos das variáveis básicas.

\subsection{Pressupostos}

Os pressupostos tem sua importância para investigar a aptidão do modelo selecionado, ou seja, verifica-se se o modelo é adequado para os propósitos ao qual se destina analisando-se cada pressuposto. Dessa forma, analisaram-se as seguintes condições para que o modelo seja adequado:

- Média zero dos resíduos;

- Homocedasticidade (variância constante): gráficos preditos versus resíduos;

- Independência serial dos resíduos (não existe autocorrelação dos erros): teste de Durbin-Watson;

- Normalidade dos resíduos: teste de Kolmogorov-Smirnov e Shapiro-Wilk ( $p$ > $0,05)$

- Outliers ou observações discrepantes: ( \pm 2 desvios-padrões);

- Seleção dos modelos possíveis: AIC (critério de informação Akaike).

Essas condições devem ser garantidas para que o modelo encontrado e a própria análise de regressão tenha a validade desejada. São acrescentados a seguir, alguns detalhamentos das informações apresentadas acima, tais como as equações utilizadas para calcular o teste de Durbin-Watson (DW) e o critério de informação Akaike (AIC), conforme (10) e (11). 


$$
\mathrm{DW}=\frac{\sum_{\mathrm{i}=2}^{\mathrm{n}}\left(\mathrm{e}_{\mathrm{i}}-\mathrm{e}_{\mathrm{i}-1}\right)^{2}}{\sum_{\mathrm{i}=1}^{\mathrm{n}}\left(\mathrm{e}_{\mathrm{i}}\right)^{2}}
$$

Sendo $e_{i}$ o resíduo associado à i-ésima observação, conforme (10). Para a realização do teste compara-se o DW calculado com os respectivos valores apresentados na tabela de Durbin-Watson, estabelecidos de acordo com o número de preditores e; o nível de significância estabelecido (GUJARATI, 2000).

No AIC, o p é o número de variáveis explicativas. O AIC aumenta conforma o SQE, sendo que valores menores de AIC são preferíveis. Os modelos com mais variáveis tendem a produzir menor SQE, mas usam mais parâmetros, a melhor escolha é balancear o ajuste com a quantidade de variáveis.

$$
\mathrm{AIC}=\mathrm{n} \cdot \log _{\mathrm{n}}\left(\frac{\mathrm{SQE}}{\mathrm{n}}\right)+2 \mathrm{p}
$$

\section{RESULTADOS}

A análise descritiva das amostras das espessuras dos anéis de crescimento dos raios de cada uma das onze árvores do município de Tapera, nas últimas seis décadas a partir de 1950 a 2009, permitiu organizar, resumir, analisar e interpretar as observações disponíveis em milímetro $(\mathrm{mm})$ das espessuras dos anéis de crescimento.

Nas Tabelas 1 a 6 tem-se a descrição da média, mediana, mínimo, máximo, desvio-padrão e coeficiente de variação para as onze árvores analisadas. Na Tabela 1, pode-se observar que a árvore 9 apresentou uma espessura mínima média de 0,36 $\mathrm{mm}$, considerando-se os quatro raios e, a árvore 4, apresentou um máximo de 6,85 $\mathrm{mm}$. A amplitude, considerando-se as médias gerais, foi de $1,38 \mathrm{~mm}$ a $3,30 \mathrm{~mm}$. A mediana variou de uma espessura geral de 1,39 mm a 2,86 mm. A árvore 11 apresentou o menor desvio-padrão médio $(0,54 \mathrm{~mm})$, com menor coeficiente médio de variação (40,44\%), enquanto que a árvore 10 apresentou a maior variação média $(75,84 \%)$. 
Tabela 1 - Análise estatística dos anéis de crescimento das onze árvores do município de Tapera para a década (1950-1959).

\begin{tabular}{|c|c|c|c|c|c|c|}
\hline \multicolumn{7}{|c|}{ Década (1950-1959) } \\
\hline Árvore 1 & Média & Mediana & Mínimo & Máximo & Desvio Padrão & C.V (\%) \\
\hline Raio 1 & 1.81 & 1.59 & 0.62 & 4.46 & 1.09 & 60.25 \\
\hline Raio 2 & 2.84 & 2.41 & 1.55 & 4.75 & 1.16 & 40.75 \\
\hline Raio 3 & 1.46 & 1.27 & 0.37 & 3.07 & 0.80 & 54.60 \\
\hline Raio 4 & 4.62 & 4.59 & 1.05 & 8.78 & 2.29 & 49.58 \\
\hline Média geral & 2.68 & 2.47 & 0.90 & 5.27 & 1.33 & 51.29 \\
\hline \multicolumn{7}{|l|}{ Árvore 2} \\
\hline Raio 1 & 1.92 & 1.99 & 0.85 & 2.68 & 0.62 & 32.10 \\
\hline Raio 2 & 3.18 & 3.11 & 1.82 & 4.94 & 0.79 & 24.99 \\
\hline Raio 3 & 1.80 & 2.26 & 0.58 & 3.14 & 1.03 & 57.18 \\
\hline Raio 4 & 1.37 & 1.13 & 0.73 & 2.80 & 0.66 & 48.66 \\
\hline Média Geral & 2.07 & 2.12 & 0.99 & 3.39 & 0.78 & 40.73 \\
\hline \multicolumn{7}{|l|}{ Árvore 3} \\
\hline Raio 1 & 4.32 & 3.12 & 0.45 & 10.81 & 3.87 & 89.47 \\
\hline Raio 2 & 1.44 & 1.05 & 0.58 & 4.42 & 1.16 & 80.59 \\
\hline Raio 3 & 1.60 & 1.24 & 0.36 & 3.96 & 1.11 & 69.20 \\
\hline Raio 4 & 2.48 & 2.32 & 0.62 & 4.50 & 1.27 & 51.13 \\
\hline Média Geral & 2.46 & 1.93 & 0.50 & 5.92 & 1.85 & 72.60 \\
\hline \multicolumn{7}{|l|}{ Árvore 4} \\
\hline Raio 1 & 3.61 & 2.81 & 1.36 & 8.54 & 2.31 & 63.88 \\
\hline Raio 2 & 3.38 & 1.75 & 0.86 & 9.87 & 3.05 & 90.47 \\
\hline Raio 3 & 3.37 & 3.35 & 0.83 & 6.06 & 1.76 & 52.24 \\
\hline Raio 4 & 1.16 & 1.00 & 0.48 & 2.95 & 0.73 & 62.54 \\
\hline Média Geral & 2.88 & 2.23 & 0.89 & 6.85 & 1.96 & 67.28 \\
\hline \multicolumn{7}{|l|}{ Árvore 5} \\
\hline Raio 1 & 2.14 & 1.92 & 0.36 & 5.81 & 1.56 & 72.68 \\
\hline Raio 2 & 1.99 & 1.68 & 0.59 & 4.56 & 1.35 & 67.81 \\
\hline Raio 3 & 2.50 & 2.75 & 0.41 & 5.88 & 1.90 & 76.07 \\
\hline Raio 4 & 1.12 & 1.03 & 0.46 & 2.21 & 0.57 & 50.30 \\
\hline Média Geral & 1.94 & 1.85 & 0.45 & 4.62 & 1.34 & 66.71 \\
\hline Árvore 6 & Média & Mediana & Mínimo & Máximo & Desvio Padrão & C.V $(\%)$ \\
\hline Raio 1 & 4.14 & 3.70 & 0.68 & 9.13 & 3.03 & 73.27 \\
\hline Raio 2 & 1.57 & 1.39 & 0.71 & 2.77 & 0.58 & 37.17 \\
\hline Raio 3 & 1.13 & 1.01 & 0.44 & 2.24 & 0.53 & 46.49 \\
\hline Raio 4 & 3.06 & 3.42 & 0.52 & 4.85 & 1.52 & 49.67 \\
\hline Média Geral & 2.48 & 2.38 & 0.58 & 4.75 & 1.42 & 51.65 \\
\hline \multicolumn{7}{|l|}{ Árvore 7} \\
\hline Raio 1 & 1.43 & 1.29 & 0.78 & 2.49 & 0.58 & 40.57 \\
\hline Raio 2 & 4.23 & 3.33 & 1.47 & 12.22 & 3.14 & 74.17 \\
\hline Raio 3 & 3.65 & 3.32 & 1.29 & 6.32 & 1.71 & 46.97 \\
\hline Raio 4 & 1.42 & 1.15 & 0.59 & 2.85 & 0.69 & 48.18 \\
\hline Média Geral & 2.68 & 2.27 & 1.03 & 5.97 & 1.53 & 52.47 \\
\hline \multicolumn{7}{|l|}{ Árvore 8} \\
\hline Raio 1 & 2.84 & 2.88 & 2.21 & 3.38 & 0.32 & 11.24 \\
\hline
\end{tabular}




\begin{tabular}{ccccccc} 
Raio 2 & 2.34 & 2.11 & 0.32 & 4.91 & 1.37 & 58.36 \\
Raio 3 & 6.04 & 4.55 & 2.27 & 15.14 & 4.20 & 69.49 \\
Raio 4 & 1.98 & 1.90 & 0.91 & 3.26 & 0.84 & 42.61 \\
Média Geral & 3.30 & 2.86 & 1.43 & 6.67 & 1.68 & 45.43 \\
\hline Árvore 9 & & & & & & \\
Raio 1 & 0.98 & 0.98 & 0.46 & 1.38 & 0.32 & 32.15 \\
Raio 2 & 0.87 & 0.77 & 0.34 & 1.35 & 0.32 & 36.81 \\
Raio 3 & 2.45 & 2.66 & 0.23 & 4.56 & 1.34 & 54.85 \\
Raio 4 & 1.45 & 1.36 & 0.41 & 2.77 & 0.90 & 62.02 \\
Média Geral & 1.44 & 1.44 & 0.36 & 2.52 & 0.72 & 46.46 \\
\hline Árvore 10 & & & & & & \\
Raio 1 & 1.58 & 1.20 & 0.35 & 5.28 & 1.57 & 99.29 \\
Raio 2 & 2.42 & 1.44 & 0.33 & 6.78 & 2.12 & 87.74 \\
Raio 3 & 1.93 & 1.42 & 0.76 & 4.92 & 1.30 & 67.36 \\
Raio 4 & 2.65 & 2.73 & 0.70 & 4.53 & 1.30 & 48.95 \\
Média Geral & 2.15 & 1.70 & 0.53 & 5.38 & 1.57 & 75.84 \\
\hline Árvore 11 & & & & & & \\
Raio 1 & 0.90 & 0.78 & 0.36 & 1.98 & 0.50 & 55.80 \\
Raio 2 & 2.37 & 2.44 & 0.97 & 3.71 & 0.90 & 37.99 \\
Raio 3 & 1.16 & 1.26 & 0.55 & 1.71 & 0.40 & 34.56 \\
Raio 4 & 1.06 & 1.10 & 0.45 & 1.58 & 0.35 & 33.42 \\
Média Geral & 1.38 & 1.39 & 0.58 & 2.24 & 0.54 & 40.44 \\
\hline Fonte: (Garcian & & & & & \\
\end{tabular}

Fonte: (Garcia- comunicação pessoal).

Na Tabela 2, pode-se observar que a árvore 2 apresentou uma espessura mínima média de 0,35 mm, considerando-se os quatro raios e, a árvore 4, apresentou um máximo de 6,42 mm. A amplitude, considerando-se as médias gerais, foi de 0,99 mm a $3,08 \mathrm{~mm}$. A mediana variou de uma espessura geral de 0,91 $\mathrm{mm}$ a 3,02 mm. A árvore 2 apresentou o menor desvio-padrão médio $(0,53 \mathrm{~mm})$, e a árvore 7 com menor coeficiente médio de variação (44,62\%), enquanto que a árvore 9 apresentou a maior variação média $(77,86 \%)$. 
Tabela 2 - Análise estatística dos anéis de crescimento das onze árvores do município de Tapera para a década (1960-1969)

\begin{tabular}{|c|c|c|c|c|c|c|}
\hline \multicolumn{7}{|c|}{ Década (1960-1969) } \\
\hline Árvore 1 & Média & Mediana & Mínimo & Máximo & Desvio Padrão & C.V (\%) \\
\hline Raio 1 & 1.99 & 1.67 & 0.54 & 4.43 & 1.41 & 70.87 \\
\hline Raio 2 & 2.25 & 2.18 & 0.82 & 3.90 & 1.18 & 52.36 \\
\hline Raio 3 & 2.22 & 2.40 & 0.61 & 4.49 & 1.35 & 60.51 \\
\hline Raio 4 & 3.18 & 3.22 & 3.22 & 6.13 & 1.42 & 44.72 \\
\hline Média Geral & 2.41 & 2.37 & 1.30 & 4.74 & 1.34 & 57.12 \\
\hline \multicolumn{7}{|l|}{ Árvore 2} \\
\hline Raio 1 & 1.03 & 0.94 & 0.44 & 2.17 & 0.59 & 57.31 \\
\hline Raio 2 & 0.84 & 0.74 & 0.37 & 1.73 & 0.46 & 54.06 \\
\hline Raio 3 & 1.48 & 1.73 & 0.23 & 2.60 & 0.95 & 63.84 \\
\hline Raio 4 & 0.59 & 0.59 & 0.36 & 0.80 & 0.13 & 22.64 \\
\hline Média Geral & 0.99 & 1.00 & 0.35 & 1.83 & 0.53 & 49.46 \\
\hline \multicolumn{7}{|l|}{ Árvore 3} \\
\hline Raio 1 & 3.43 & 3.11 & 0.38 & 7.24 & 2.55 & 74.43 \\
\hline Raio 2 & 1.82 & 1.62 & 0.84 & 3.98 & 1.01 & 55.67 \\
\hline Raio 3 & 1.92 & 1.93 & 0.40 & 4.28 & 1.22 & 63.71 \\
\hline Raio 4 & 1.58 & 1.45 & 0.36 & 3.33 & 1.00 & 63.08 \\
\hline Média Geral & 2.19 & 2.03 & 0.50 & 4.71 & 1.45 & 64.22 \\
\hline \multicolumn{7}{|l|}{ Árvore 4} \\
\hline Raio 1 & 1.47 & 1.46 & 0.54 & 2.90 & 0.73 & 49.56 \\
\hline Raio 2 & 2.73 & 1.97 & 0.78 & 8.02 & 2.23 & 81.76 \\
\hline Raio 3 & 2.89 & 2.73 & 0.32 & 5.16 & 1.89 & 65.22 \\
\hline Raio 4 & 4.66 & 3.82 & 1.68 & 9.62 & 2.66 & 57.08 \\
\hline Média Geral & 2.94 & 2.49 & 0.83 & 6.42 & 1.88 & 63.40 \\
\hline \multicolumn{7}{|l|}{ Árvore 5} \\
\hline Raio 1 & 1.74 & 1.09 & 0.64 & 4.43 & 1.28 & 73.59 \\
\hline Raio 2 & 3.40 & 2.02 & 0.59 & 10.04 & 3.11 & 91.31 \\
\hline Raio 3 & 1.41 & 1.14 & 0.51 & 2.81 & 0.91 & 64.46 \\
\hline Raio 4 & 2.56 & 2.68 & 0.64 & 4.62 & 1.20 & 47.01 \\
\hline Média Geral & 2.28 & 1.73 & 0.59 & 5.48 & 1.63 & 69.09 \\
\hline \multicolumn{7}{|c|}{ Década (1960-1969) } \\
\hline Árvore 6 & Média & Mediana & Mínimo & Máximo & Desvio Padrão & C.V (\%) \\
\hline Raio 1 & 4.24 & 3.81 & 2.82 & 6.26 & 1.03 & 24.22 \\
\hline Raio 2 & 0.99 & 0.79 & 0.34 & 2.82 & 0.75 & 75.97 \\
\hline Raio 3 & 2.73 & 2.44 & 0.57 & 6.05 & 1.76 & 64.33 \\
\hline Raio 4 & 2.66 & 2.52 & 0.47 & 6.53 & 2.08 & 78.27 \\
\hline Média Geral & 2.66 & 2.39 & 1.05 & 5.41 & 1.40 & 60.70 \\
\hline \multicolumn{7}{|l|}{ Árvore 7} \\
\hline Raio 1 & 1.10 & 0.84 & 0.62 & 2.09 & 0.55 & 50.42 \\
\hline Raio 2 & 5.60 & 5.16 & 2.17 & 12.56 & 2.84 & 50.76 \\
\hline Raio 3 & 3.41 & 3.75 & 2.04 & 4.69 & 0.97 & 28.47 \\
\hline Raio 4 & 2.20 & 2.33 & 0.56 & 4.20 & 1.07 & 48.82 \\
\hline Média Geral & 3.08 & 3.02 & 1.35 & 5.88 & 1.36 & 44.62 \\
\hline \multicolumn{7}{|l|}{ Árvore 8} \\
\hline Raio 1 & 1.63 & 1.53 & 0.61 & 3.47 & 0.97 & 59.85 \\
\hline
\end{tabular}




\begin{tabular}{lcccccc}
\hline Raio 2 & 1.91 & 1.81 & 0.69 & 3.64 & 1.01 & 52.95 \\
Raio 3 & 3.25 & 3.22 & 1.12 & 7.27 & 1.79 & 55.07 \\
Raio 4 & 1.73 & 1.76 & 0.47 & 3.03 & 0.84 & 48.21 \\
Média Geral & 2.13 & 2.08 & 0.72 & 4.35 & 1.15 & 54.02 \\
\hline Árvore 9 & & & & & & \\
Raio 1 & 2.09 & 1.08 & 0.40 & 9.58 & 2.73 & 130.42 \\
Raio 2 & 1.05 & 0.78 & 0.27 & 2.06 & 0.56 & 53.25 \\
Raio 3 & 1.15 & 0.90 & 0.38 & 2.38 & 0.77 & 67.09 \\
Raio 4 & 2.43 & 2.27 & 0.56 & 4.65 & 1.48 & 60.70 \\
Média Geral & 1.68 & 1.26 & 0.40 & 4.67 & 1.38 & 77.86 \\
\hline Árvore 10 & & & & & & \\
Raio 1 & 1.80 & 1.36 & 0.27 & 4.47 & 1.24 & 69.10 \\
Raio 2 & 2.63 & 2.12 & 0.52 & 8.53 & 2.37 & 89.98 \\
Raio 3 & 2.62 & 2.85 & 0.64 & 4.64 & 1.39 & 53.10 \\
Raio 4 & 3.23 & 2.89 & 0.84 & 7.22 & 1.91 & 59.24 \\
Média Geral & 2.57 & 2.30 & 0.57 & 6.22 & 1.73 & 67.85 \\
\hline Árvore 11 & & & & & & \\
Raio 1 & 1.43 & 1.12 & 0.76 & 2.59 & 0.64 & 44.96 \\
Raio 2 & 1.38 & 1.24 & 0.57 & 3.19 & 0.86 & 62.45 \\
Raio 3 & 0.93 & 0.66 & 0.26 & 1.88 & 0.55 & 59.09 \\
Raio 4 & 0.57 & 0.61 & 0.36 & 0.76 & 0.12 & 20.51 \\
Média Geral & 1.08 & 0.91 & 0.49 & 2.11 & 0.54 & 46.75 \\
\hline Fonte: (Garcia- comunicação pessoal). & & & &
\end{tabular}

Na Tabela 3, pode-se observar que a árvore 2 apresentou uma espessura mínima média de 0,34 mm, considerando-se os quatro raios e, a árvore 10, apresentou um máximo de 7,67 mm. A amplitude, considerando-se as médias gerais, foi de 1,25 mm a 3,55 mm. A mediana variou de uma espessura geral de 0,94 $\mathrm{mm}$ a 2,84 mm. A árvore 7 apresentou o menor desvio-padrão médio $(0,52 \mathrm{~mm})$, com menor coeficiente médio de variação (44,96\%), enquanto que a árvore 4 apresentou a maior variação média $(69,67 \%)$. 
Tabela 3 - Análise estatística dos anéis de crescimento das onze árvores do município de Tapera para a década (1970 - 1979).

\begin{tabular}{|c|c|c|c|c|c|c|}
\hline \multicolumn{7}{|c|}{ Década (1970-1979) } \\
\hline Árvore 1 & Média & Mediana & Mínimo & Máximo & Desvio Padrão & C.V $(\%)$ \\
\hline Raio 1 & 2.56 & 2.21 & 1.07 & 4.49 & 1.10 & 42.88 \\
\hline Raio 2 & 0.48 & 0.38 & 0.25 & 1.14 & 0.30 & 62.57 \\
\hline Raio 3 & 2.55 & 3.49 & 0.37 & 4.20 & 1.51 & 59.09 \\
\hline Raio 4 & 2.00 & 1.92 & 0.67 & 3.85 & 0.93 & 46.72 \\
\hline Média Geral & 1.90 & 2.00 & 0.59 & 3.42 & 0.96 & 52.81 \\
\hline \multicolumn{7}{|l|}{ Árvore 2} \\
\hline Raio 1 & 1.03 & 0.89 & 0.41 & 2.47 & 0.64 & 62.07 \\
\hline Raio 2 & 1.63 & 1.93 & 0.29 & 3.07 & 1.10 & 67.57 \\
\hline Raio 3 & 1.42 & 1.50 & 0.26 & 2.49 & 0.86 & 60.56 \\
\hline Raio 4 & 0.92 & 0.80 & 0.40 & 2.14 & 0.55 & 59.27 \\
\hline Média Geral & 1.25 & 1.28 & 0.34 & 2.54 & 0.79 & 62.37 \\
\hline \multicolumn{7}{|l|}{ Árvore 3} \\
\hline Raio 1 & 1.33 & 0.81 & 0.26 & 4.19 & 1.22 & 91.86 \\
\hline Raio 2 & 2.38 & 1.84 & 0.61 & 5.20 & 1.60 & 66.98 \\
\hline Raio 3 & 2.52 & 2.36 & 0.82 & 4.54 & 1.35 & 53.60 \\
\hline Raio 4 & 3.13 & 3.23 & 0.59 & 4.76 & 1.31 & 41.93 \\
\hline Média Geral & 2.34 & 2.06 & 0.57 & 4.67 & 1.37 & 63.59 \\
\hline \multicolumn{7}{|l|}{ Árvore 4} \\
\hline Raio 1 & 1.13 & 0.99 & 0.38 & 2.36 & 0.61 & 53.90 \\
\hline Raio 2 & 2.33 & 1.92 & 0.36 & 6.52 & 1.85 & 79.36 \\
\hline Raio 3 & 1.65 & 1.16 & 0.62 & 5.68 & 1.51 & 91.89 \\
\hline Raio 4 & 2.24 & 2.21 & 0.80 & 3.67 & 1.20 & 53.51 \\
\hline Média Geral & 1.84 & 1.57 & 0.54 & 4.56 & 1.29 & 69.67 \\
\hline \multicolumn{7}{|l|}{ Árvore 5} \\
\hline Raio 1 & 2.27 & 1.95 & 0.57 & 4.96 & 1.44 & 63.36 \\
\hline Raio 2 & 3.57 & 3.00 & 1.10 & 8.09 & 2.45 & 68.59 \\
\hline Raio 3 & 1.49 & 1.45 & 0.93 & 2.28 & 0.45 & 30.11 \\
\hline Raio 4 & 1.36 & 1.25 & 0.47 & 3.28 & 0.78 & 57.25 \\
\hline Média Geral & 2.17 & 1.91 & 0.77 & 4.65 & 1.28 & 54.83 \\
\hline \multicolumn{7}{|c|}{ Década (1970-1979) } \\
\hline Árvore 6 & Média & Mediana & Mínimo & Máximo & Desvio Padrão & C.V $(\%)$ \\
\hline Raio 1 & 3.95 & 2.66 & 1.12 & 10.56 & 3.06 & 77.48 \\
\hline Raio 2 & 0.93 & 0.78 & 0.32 & 1.96 & 0.54 & 58.41 \\
\hline Raio 3 & 2.85 & 2.85 & 1.46 & 4.57 & 1.00 & 35.06 \\
\hline Raio 4 & 3.16 & 3.08 & 0.65 & 5.75 & 1.84 & 58.32 \\
\hline Média Geral & 2.72 & 2.34 & 0.89 & 5.71 & 1.61 & 57.32 \\
\hline \multicolumn{7}{|l|}{ Árvore 7} \\
\hline Raio 1 & 0.61 & 0.51 & 0.40 & 1.11 & 0.26 & 42.41 \\
\hline Raio 2 & 1.79 & 1.44 & 0.74 & 3.12 & 1.00 & 55.89 \\
\hline Raio 3 & 0.59 & 0.58 & 0.29 & 0.98 & 0.20 & 34.81 \\
\hline Raio 4 & 1.32 & 1.22 & 0.35 & 2.24 & 0.61 & 46.74 \\
\hline Média Geral & 1.08 & 0.94 & 0.44 & 1.86 & 0.52 & 44.96 \\
\hline \multicolumn{7}{|l|}{ Árvore 8} \\
\hline Raio 1 & 0.77 & 0.84 & 0.29 & 1.32 & 0.38 & 49.49 \\
\hline
\end{tabular}




\begin{tabular}{lcccccc}
\hline Raio 2 & 1.49 & 1.44 & 0.64 & 2.55 & 0.70 & 47.25 \\
Raio 3 & 1.31 & 1.04 & 0.23 & 4.54 & 1.17 & 89.57 \\
Raio 4 & 1.13 & 1.13 & 0.30 & 2.06 & 0.62 & 55.18 \\
Média Geral & 1.17 & 1.11 & 0.36 & 2.62 & 0.72 & 60.37 \\
\hline Árvore 9 & & & & & & \\
Raio 1 & 2.40 & 2.34 & 0.51 & 5.18 & 1.59 & 66.45 \\
Raio 2 & 2.69 & 2.71 & 1.02 & 3.56 & 0.76 & 28.06 \\
Raio 3 & 0.81 & 0.50 & 0.28 & 2.80 & 0.77 & 95.06 \\
Raio 4 & 1.28 & 1.31 & 0.31 & 2.07 & 0.59 & 46.22 \\
Média Geral & 1.80 & 1.72 & 0.53 & 3.40 & 0.93 & 58.95 \\
\hline Árvore 10 & & & & & & \\
Raio 1 & 2.94 & 2.17 & 0.56 & 5.76 & 2.13 & 72.58 \\
Raio 2 & 2.07 & 2.07 & 1.00 & 3.87 & 0.81 & 39.42 \\
Raio 3 & 5.21 & 3.49 & 1.53 & 13.83 & 4.06 & 77.98 \\
Raio 4 & 4.00 & 3.64 & 2.12 & 7.20 & 1.61 & 40.17 \\
Média Geral & 3.55 & 2.84 & 1.30 & 7.67 & 2.15 & 57.54 \\
\hline Árvore 11 & & & & & & \\
Raio 1 & 0.89 & 0.82 & 0.39 & 1.91 & 0.43 & 48.34 \\
Raio 2 & 2.64 & 2.14 & 0.76 & 6.20 & 1.90 & 71.91 \\
Raio 3 & 1.00 & 0.73 & 0.47 & 2.35 & 0.66 & 66.19 \\
Raio 4 & 0.49 & 0.42 & 0.35 & 0.90 & 0.18 & 36.69 \\
Média Geral & 1.25 & 1.03 & 0.49 & 2.84 & 0.79 & 55.78 \\
\hline Fonte: (Garcia- comunicação pessoal). & & & &
\end{tabular}

Fonte: (Garcia- comunicação pessoal).

Na Tabela 4, pode-se observar que a árvore 1 apresentou uma espessura mínima média de 0,32 mm, considerando-se os quatro raios e, a árvore 2, apresentou um máximo de 6,35 mm. A amplitude, considerando-se as médias gerais, foi de 0,89 mm a 2,98 $\mathrm{mm}$. A mediana variou de uma espessura geral de $0,75 \mathrm{~mm}$ a 2,81 $\mathrm{mm}$. As árvores 1 e 7 apresentaram o menor desvio-padrão médio $(0,54 \mathrm{~mm})$, a árvore 3 com menor coeficiente médio de variação (48,76\%), enquanto que a árvore 11 apresentou a maior variação média $(73,90 \%)$. 
Tabela 4 - Análise estatística dos anéis de crescimento das onze árvores do município de Tapera para a década (1980 - 1989).

\begin{tabular}{|c|c|c|c|c|c|c|}
\hline \multicolumn{7}{|c|}{ Década (1980-1989) } \\
\hline Árvore 1 & Média & Mediana & Mínimo & Máximo & Desvio Padrão & C.V $(\%)$ \\
\hline Raio 1 & 1.15 & 1.01 & 0.44 & 2.16 & 0.59 & 51.60 \\
\hline Raio 2 & 0.82 & 0.62 & 0.26 & 2.27 & 0.62 & 75.18 \\
\hline Raio 3 & 0.96 & 0.96 & 0.34 & 2.04 & 0.52 & 54.02 \\
\hline Raio 4 & 0.57 & 0.43 & 0.23 & 1.69 & 0.44 & 76.18 \\
\hline $\begin{array}{l}\text { Média Geral } \\
\text { Árvore } 2\end{array}$ & 0.89 & 0.76 & 0.32 & 2.04 & 0.54 & 64.24 \\
\hline Raio 1 & 1.38 & 1.26 & 0.41 & 2.75 & 0.77 & 55.70 \\
\hline Raio 2 & 1.45 & 1.37 & 0.32 & 4.27 & 1.16 & 79.73 \\
\hline Raio 3 & 4.40 & 3.63 & 0.80 & 10.77 & 3.35 & 76.10 \\
\hline Raio 4 & 4.70 & 4.99 & 1.95 & 7.61 & 1.71 & 36.50 \\
\hline $\begin{array}{l}\text { Média Geral } \\
\text { Árvore } 3\end{array}$ & 2.98 & 2.81 & 0.87 & 6.35 & 1.75 & 62.01 \\
\hline Raio 1 & 0.96 & 0.89 & 0.22 & 1.97 & 0.48 & 50.07 \\
\hline Raio 2 & 0.67 & 0.58 & 0.34 & 1.10 & 0.30 & 44.99 \\
\hline Raio 3 & 0.79 & 0.76 & 0.30 & 1.19 & 0.29 & 36.40 \\
\hline Raio 4 & 1.88 & 1.23 & 0.67 & 4.06 & 1.19 & 63.58 \\
\hline $\begin{array}{l}\text { Média Geral } \\
\text { Árvore } 4\end{array}$ & 1.08 & 0.87 & 0.38 & 2.08 & 0.57 & 48.76 \\
\hline Raio 1 & 1.80 & 1.19 & 0.34 & 4.08 & 1.42 & 78.78 \\
\hline Raio 2 & 1.51 & 1.08 & 0.40 & 3.79 & 1.14 & 75.35 \\
\hline Raio 3 & 1.31 & 0.91 & 0.34 & 2.96 & 1.02 & 78.07 \\
\hline Raio 4 & 2.53 & 2.68 & 0.64 & 5.58 & 1.60 & 63.04 \\
\hline $\begin{array}{l}\text { Média Geral } \\
\text { Árvore } 5\end{array}$ & 1.79 & 1.46 & 0.43 & 4.10 & 1.29 & 73.81 \\
\hline Raio 1 & 1.91 & 1.04 & 0.42 & 5.36 & 1.78 & 92.95 \\
\hline Raio 2 & 1.72 & 1.36 & 0.40 & 4.22 & 1.24 & 72.33 \\
\hline Raio 3 & 1.20 & 0.94 & 0.35 & 2.77 & 0.79 & 66.05 \\
\hline Raio 4 & 1.76 & 1.64 & 0.31 & 3.56 & 1.06 & 60.33 \\
\hline Média Geral & 1.65 & 1.25 & 0.37 & 3.98 & 1.22 & 72.92 \\
\hline \multicolumn{7}{|c|}{ Década (1980-1989) } \\
\hline Árvore 6 & Média & Mediana & Mínimo & Máximo & Desvio Padrão & C.V (\%) \\
\hline Raio 1 & 3.55 & 2.72 & 0.41 & 7.34 & 2.43 & 68.47 \\
\hline Raio 2 & 1.34 & 1.05 & 0.39 & 2.55 & 0.72 & 54.00 \\
\hline Raio 3 & 2.72 & 2.31 & 0.75 & 4.91 & 1.31 & 48.17 \\
\hline Raio 4 & 3.81 & 3.16 & 1.75 & 7.17 & 1.88 & 49.36 \\
\hline $\begin{array}{l}\text { Média Geral } \\
\text { Árvore } 7\end{array}$ & 2.85 & 2.31 & 0.82 & 5.49 & 1.59 & 55.00 \\
\hline Raio 1 & 0.51 & 0.46 & 0.31 & 0.85 & 0.19 & 36.43 \\
\hline Raio 2 & 1.50 & 1.41 & 0.50 & 2.82 & 0.68 & 44.99 \\
\hline Raio 3 & 1.28 & 1.27 & 0.39 & 2.12 & 0.58 & 44.93 \\
\hline Raio 4 & 0.90 & 0.69 & 0.33 & 2.89 & 0.74 & 82.08 \\
\hline $\begin{array}{l}\text { Média Geral } \\
\text { Árvore } 8\end{array}$ & 1.05 & 0.96 & 0.38 & 2.17 & 0.54 & 52.11 \\
\hline Raio 1 & 1.28 & 1.11 & 0.18 & 3.25 & 0.91 & 70.94 \\
\hline
\end{tabular}




\begin{tabular}{lllllll}
\hline Raio 2 & 0.90 & 0.60 & 0.28 & 2.62 & 0.79 & 88.16 \\
Raio 3 & 3.96 & 3.98 & 0.92 & 6.32 & 1.46 & 36.87 \\
Raio 4 & 0.61 & 0.55 & 0.28 & 1.01 & 0.21 & 34.15 \\
Média Geral & 1.69 & 1.56 & 0.42 & 3.30 & 0.84 & 57.53 \\
Árvore 9 & & & & & & \\
Raio 1 & 3.19 & 2.91 & 0.98 & 6.59 & 1.68 & 52.79 \\
Raio 2 & 1.04 & 0.57 & 0.36 & 2.52 & 0.80 & 76.81 \\
Raio 3 & 2.35 & 1.20 & 0.34 & 6.93 & 2.20 & 93.63 \\
Raio 4 & 3.09 & 2.51 & 1.17 & 6.46 & 1.82 & 58.97 \\
Média Geral & 2.42 & 1.80 & 0.71 & 5.62 & 1.62 & 70.55 \\
Árvore 10 & & & & & & \\
Raio 1 & 2.24 & 2.28 & 0.44 & 4.35 & 1.08 & 48.30 \\
Raio 2 & 1.57 & 1.26 & 0.19 & 4.59 & 1.39 & 88.66 \\
Raio 3 & 3.48 & 3.01 & 0.50 & 7.38 & 2.44 & 70.23 \\
Raio 4 & 2.41 & 2.10 & 0.65 & 5.06 & 1.61 & 66.74 \\
Média Geral & 2.43 & 2.16 & 0.45 & 5.35 & 1.63 & 68.48 \\
Árvore 11 & & & & & & \\
Raio 1 & 1.16 & 0.76 & 0.38 & 4.13 & 1.12 & 96.80 \\
Raio 2 & 1.49 & 1.26 & 0.39 & 2.86 & 0.82 & 55.12 \\
Raio 3 & 0.41 & 0.33 & 0.25 & 0.99 & 0.22 & 53.73 \\
Raio 4 & 0.84 & 0.62 & 0.30 & 2.89 & 0.76 & 89.95 \\
Média Geral & 0.97 & 0.75 & 0.33 & 2.72 & 0.73 & 73.90 \\
\hline Fonte: (Garcia- comunicação pessoal). & & & &
\end{tabular}

Na Tabela 5, pode-se observar que a árvore 8 apresentou uma espessura mínima média de 0,34 mm, considerando-se os quatro raios e, a árvore 2, apresentou um máximo de 7,23 mm. A amplitude, considerando-se as médias gerais, foi de 0,98 $\mathrm{mm}$ a 3,69 mm. A mediana variou de uma espessura geral de 0,86 $\mathrm{mm}$ a 3,61 mm. A árvore 7 apresentou o menor desvio-padrão médio $(0,47 \mathrm{~mm})$, a árvore 11 com menor coeficiente médio de variação $(41,84 \%)$, enquanto que a árvore 1 apresentou a maior variação média (78,79\%). 
Tabela 5 - Análise estatística dos anéis de crescimento das onze árvores do município de tapera para a década (1990 - 1999).

\begin{tabular}{|c|c|c|c|c|c|c|}
\hline \multicolumn{7}{|c|}{ Década (1990-1999) } \\
\hline Árvore 1 & Média & Mediana & Mínimo & Máximo & Desvio Padrão & C.V $(\%)$ \\
\hline Raio 1 & 2.94 & 2.15 & 0.86 & 10.49 & 2.79 & 94.87 \\
\hline Raio 2 & 1.79 & 1.72 & 0.49 & 3.60 & 1.07 & 59.76 \\
\hline Raio 3 & 1.57 & 1.58 & 0.47 & 4.21 & 1.12 & 71.56 \\
\hline Raio 4 & 3.27 & 2.03 & 0.96 & 8.97 & 2.91 & 88.97 \\
\hline Média Geral & 2.39 & 1.87 & 0.70 & 6.82 & 1.97 & 78.79 \\
\hline \multicolumn{7}{|l|}{ Árvore 2} \\
\hline Raio 1 & 3.50 & 3.04 & 0.99 & 7.07 & 2.14 & 61.24 \\
\hline Raio 2 & 3.11 & 2.67 & 0.53 & 7.77 & 2.10 & 67.42 \\
\hline Raio 3 & 4.57 & 4.65 & 2.07 & 8.23 & 1.85 & 40.35 \\
\hline Raio 4 & 3.56 & 3.81 & 1.02 & 5.87 & 1.58 & 44.51 \\
\hline Média Geral & 3.69 & 3.54 & 1.15 & 7.23 & 1.92 & 53.38 \\
\hline \multicolumn{7}{|l|}{ Árvore 3} \\
\hline Raio 1 & 2.74 & 2.67 & 0.16 & 6.26 & 2.00 & 73.05 \\
\hline Raio 2 & 2.78 & 2.65 & 1.23 & 4.43 & 1.15 & 41.23 \\
\hline Raio 3 & 2.64 & 2.93 & 0.50 & 4.50 & 1.56 & 59.08 \\
\hline Raio 4 & 2.88 & 2.52 & 0.57 & 7.77 & 2.06 & 71.56 \\
\hline Média Geral & 2.76 & 2.69 & 0.61 & 5.74 & 1.69 & 61.23 \\
\hline \multicolumn{7}{|l|}{ Árvore 4} \\
\hline Raio 1 & 2.62 & 1.96 & 0.85 & 7.68 & 1.90 & 72.30 \\
\hline Raio 2 & 2.40 & 2.46 & 0.89 & 4.21 & 1.02 & 42.38 \\
\hline Raio 3 & 0.83 & 0.86 & 0.43 & 1.40 & 0.27 & 32.85 \\
\hline Raio 4 & 2.62 & 1.93 & 0.66 & 8.38 & 2.24 & 85.40 \\
\hline Média Geral & 2.12 & 1.80 & 0.71 & 5.42 & 1.36 & 58.23 \\
\hline \multicolumn{7}{|l|}{ Árvore 5} \\
\hline Raio 1 & 2.37 & 2.09 & 0.86 & 4.02 & 1.15 & 48.49 \\
\hline Raio 2 & 4.29 & 3.94 & 2.46 & 6.03 & 1.35 & 31.51 \\
\hline Raio 3 & 0.91 & 0.87 & 0.30 & 1.69 & 0.50 & 54.96 \\
\hline Raio 4 & 1.21 & 0.92 & 0.23 & 2.67 & 0.81 & 66.61 \\
\hline Média Geral & 2.19 & 1.95 & 0.96 & 3.60 & 0.95 & 50.39 \\
\hline \multicolumn{7}{|c|}{ Década (1990-1999) } \\
\hline Árvore 6 & Média & Mediana & Mínimo & Máximo & Desvio Padrão & C.V (\%) \\
\hline Raio 1 & 5.72 & 5.66 & 3.07 & 10.77 & 2.28 & 39.94 \\
\hline Raio 2 & 1.79 & 1.72 & 0.62 & 2.88 & 0.94 & 52.52 \\
\hline Raio 3 & 2.38 & 2.39 & 0.92 & 4.33 & 1.01 & 42.72 \\
\hline Raio 4 & 4.60 & 4.69 & 1.72 & 7.40 & 1.55 & 33.60 \\
\hline Média Geral & 3.62 & 3.61 & 1.58 & 6.34 & 1.45 & 42.19 \\
\hline \multicolumn{7}{|l|}{ Árvore 7} \\
\hline Raio 1 & 0.95 & 0.89 & 0.39 & 1.46 & 0.35 & 37.00 \\
\hline Raio 2 & 1.12 & 1.19 & 0.23 & 2.10 & 0.51 & 45.69 \\
\hline Raio 3 & 1.70 & 1.75 & 0.56 & 2.93 & 0.70 & 41.58 \\
\hline Raio 4 & 0.67 & 0.59 & 0.30 & 1.37 & 0.31 & 46.26 \\
\hline Média Geral & 1.11 & 1.11 & 0.37 & 1.97 & 0.47 & 42.63 \\
\hline \multicolumn{7}{|l|}{ Árvore 8} \\
\hline Raio 1 & 0.77 & 0.84 & 0.31 & 1.12 & 0.30 & 38.60 \\
\hline
\end{tabular}




\begin{tabular}{lcccccc}
\hline Raio 2 & 2.69 & 2.41 & 0.40 & 7.39 & 2.33 & 86.67 \\
Raio 3 & 1.45 & 0.80 & 0.40 & 3.69 & 1.18 & 81.60 \\
Raio 4 & 0.70 & 0.48 & 0.23 & 1.43 & 0.42 & 60.83 \\
Média Geral & 1.40 & 1.13 & 0.34 & 3.41 & 1.06 & 66.93 \\
\hline Árvore 9 & & & & & & \\
Raio 1 & 0.60 & 0.41 & 0.26 & 1.30 & 0.40 & 66.46 \\
Raio 2 & 1.59 & 1.53 & 0.39 & 2.57 & 0.75 & 47.42 \\
Raio 3 & 0.91 & 0.75 & 0.22 & 2.82 & 0.73 & 80.06 \\
Raio 4 & 1.16 & 0.75 & 0.54 & 2.68 & 0.79 & 68.10 \\
Média Geral & 1.06 & 0.86 & 0.35 & 2.34 & 0.67 & 65.51 \\
\hline Árvore 10 & & & & & & \\
Raio 1 & 2.50 & 2.11 & 0.57 & 5.58 & 1.92 & 76.83 \\
Raio 2 & 3.96 & 3.78 & 0.83 & 9.20 & 2.29 & 57.87 \\
Raio 3 & 2.12 & 1.58 & 0.27 & 5.07 & 1.85 & 87.25 \\
Raio 4 & 1.46 & 1.64 & 0.48 & 2.49 & 0.78 & 53.67 \\
Média Geral & 2.51 & 2.27 & 0.54 & 5.58 & 1.71 & 68.90 \\
\hline Árvore 11 & & & & & & \\
Raio 1 & 1.62 & 1.32 & 0.51 & 4.75 & 1.26 & 77.46 \\
Raio 2 & 0.92 & 0.88 & 0.62 & 1.65 & 0.32 & 34.98 \\
Raio 3 & 0.51 & 0.47 & 0.38 & 0.76 & 0.11 & 21.28 \\
Raio 4 & 0.86 & 0.93 & 0.41 & 1.19 & 0.29 & 33.64 \\
Média Geral & 0.98 & 0.90 & 0.48 & 2.09 & 0.49 & 41.84 \\
\hline Fonte: (Garcia- comunicãa 9 ssoal) & & & &
\end{tabular}

Na Tabela 6, pode-se observar que a árvore 9 apresentou uma espessura mínima média de 0,28 mm, considerando-se os quatro raios e, a árvore 3, apresentou um máximo de 6,61 mm. A amplitude, considerando-se as médias gerais, foi de 0,88 $\mathrm{mm}$ a 3,01 mm. A mediana variou de uma espessura geral de 0,74 $\mathrm{mm}$ a 2,69 mm. A árvore 5 apresentou o menor desvio-padrão médio $(0,47 \mathrm{~mm})$, a árvore 8 com menor coeficiente médio de variação $(35,43 \%)$, enquanto que a árvore 4 apresentou a maior variação média $(87,78 \%)$. 
Tabela 6 - Análise estatística dos anéis de crescimento das onze árvores do município de Tapera para a década (2000 - 2009).

\begin{tabular}{|c|c|c|c|c|c|c|}
\hline \multicolumn{7}{|c|}{ Década (2000-2009) } \\
\hline Árvore 1 & Média & Mediana & Mínimo & Máximo & Desvio Padrão & C.V $(\%)$ \\
\hline Raio 1 & 1.90 & 1.70 & 0.60 & 3.77 & 1.11 & 58.29 \\
\hline Raio 2 & 0.95 & 0.86 & 0.42 & 1.69 & 0.44 & 46.60 \\
\hline Raio 3 & 0.53 & 0.46 & 0.41 & 0.88 & 0.15 & 28.87 \\
\hline Raio 4 & 1.66 & 1.45 & 0.37 & 3.67 & 1.25 & 75.11 \\
\hline Média Geral & 1.26 & 1.12 & 0.45 & 2.50 & 0.74 & 52.22 \\
\hline \multicolumn{7}{|l|}{ Árvore 2} \\
\hline Raio 1 & 1.54 & 1.10 & 0.40 & 3.94 & 1.11 & 72.25 \\
\hline Raio 2 & 1.69 & 1.14 & 0.42 & 5.65 & 1.63 & 96.30 \\
\hline Raio 3 & 4.36 & 4.15 & 0.38 & 9.13 & 3.19 & 73.08 \\
\hline Raio 4 & 3.77 & 4.18 & 0.33 & 6.42 & 1.95 & 51.83 \\
\hline Média Geral & 2.84 & 2.64 & 0.38 & 6.28 & 1.97 & 73.37 \\
\hline \multicolumn{7}{|l|}{ Árvore 3} \\
\hline Raio 1 & 1.20 & 0.96 & 0.62 & 2.73 & 0.64 & 53.60 \\
\hline Raio 2 & 3.54 & 2.29 & 1.45 & 10.07 & 2.81 & 79.30 \\
\hline Raio 3 & 2.60 & 1.71 & 0.62 & 6.75 & 1.99 & 76.31 \\
\hline Raio 4 & 2.58 & 1.69 & 0.34 & 6.88 & 2.48 & 95.95 \\
\hline Média Geral & 2.48 & 1.66 & 0.76 & 6.61 & 1.98 & 76.29 \\
\hline \multicolumn{7}{|l|}{ Árvore 4} \\
\hline Raio 1 & 1.45 & 1.45 & 0.48 & 3.29 & 0.85 & 58.57 \\
\hline Raio 2 & 3.27 & 2.18 & 0.65 & 7.89 & 2.62 & 80.11 \\
\hline Raio 3 & 1.41 & 1.14 & 0.61 & 3.13 & 0.80 & 57.14 \\
\hline Raio 4 & 1.19 & 0.55 & 0.23 & 6.37 & 1.85 & 155.30 \\
\hline Média Geral & 1.83 & 1.33 & 0.49 & 5.17 & 1.53 & 87.78 \\
\hline \multicolumn{7}{|l|}{ Árvore 5} \\
\hline Raio 1 & 1.10 & 0.77 & 0.50 & 2.78 & 0.78 & 71.48 \\
\hline Raio 2 & 0.79 & 0.76 & 0.35 & 1.67 & 0.36 & 45.15 \\
\hline Raio 3 & 0.73 & 0.79 & 0.41 & 1.05 & 0.22 & 30.47 \\
\hline Raio 4 & 0.92 & 0.77 & 0.43 & 2.05 & 0.51 & 55.97 \\
\hline Média Geral & 0.88 & 0.77 & 0.42 & 1.89 & 0.47 & 50.77 \\
\hline \multicolumn{7}{|c|}{ Década (2000-2009) } \\
\hline Árvore 6 & Média & Mediana & Mínimo & Máximo & Desvio Padrão & C.V $(\%)$ \\
\hline Raio 1 & 4.38 & 4.61 & 0.77 & 8.23 & 2.48 & 56.59 \\
\hline Raio 2 & 1.30 & 0.96 & 0.42 & 2.70 & 0.84 & 64.74 \\
\hline Raio 3 & 2.34 & 2.09 & 0.40 & 4.47 & 1.36 & 58.41 \\
\hline Raio 4 & 3.50 & 3.49 & 0.89 & 6.42 & 2.03 & 57.98 \\
\hline Média Geral & 2.88 & 2.79 & 0.62 & 5.45 & 1.68 & 59.43 \\
\hline \multicolumn{7}{|l|}{ Árvore 7} \\
\hline Raio 1 & 0.63 & 0.65 & 0.45 & 0.81 & 0.14 & 21.36 \\
\hline Raio 2 & 2.77 & 1.49 & 0.70 & 10.07 & 2.97 & 107.03 \\
\hline Raio 3 & 1.00 & 0.70 & 0.28 & 2.12 & 0.64 & 63.58 \\
\hline Raio 4 & 0.83 & 0.78 & 0.27 & 2.08 & 0.60 & 72.28 \\
\hline Média Geral & 1.31 & 0.90 & 0.43 & 3.77 & 1.08 & 66.06 \\
\hline \multicolumn{7}{|l|}{ Árvore 8} \\
\hline Raio 1 & 2.34 & 2.17 & 1.12 & 3.85 & 0.97 & 41.44 \\
\hline
\end{tabular}




\begin{tabular}{lcccccc}
\hline Raio 2 & 2.31 & 2.12 & 1.23 & 4.05 & 0.95 & 41.02 \\
Raio 3 & 4.27 & 4.39 & 1.37 & 6.76 & 1.61 & 37.80 \\
Raio 4 & 2.34 & 2.47 & 1.43 & 2.96 & 0.50 & 21.46 \\
Média Geral & 2.81 & 2.79 & 1.29 & 4.41 & 1.01 & 35.43 \\
\hline Árvore 9 & & & & & & \\
Raio 1 & 0.81 & 0.72 & 0.33 & 1.61 & 0.39 & 47.89 \\
Raio 2 & 1.17 & 0.64 & 0.26 & 2.87 & 0.97 & 83.14 \\
Raio 3 & 0.68 & 0.54 & 0.21 & 1.75 & 0.45 & 65.29 \\
Raio 4 & 1.18 & 1.05 & 0.33 & 2.57 & 0.79 & 66.78 \\
Média Geral & 0.96 & 0.74 & 0.28 & 2.20 & 0.65 & 65.77 \\
\hline Árvore 10 & & & & & & \\
Raio 1 & 4.05 & 3.90 & 1.42 & 6.59 & 1.90 & 46.82 \\
Raio 2 & 1.57 & 1.16 & 0.46 & 3.20 & 0.90 & 57.10 \\
Raio 3 & 4.22 & 3.29 & 0.74 & 8.92 & 3.00 & 71.13 \\
Raio 4 & 2.19 & 2.00 & 0.83 & 3.90 & 1.09 & 49.69 \\
Média Geral & 3.01 & 2.59 & 0.86 & 5.65 & 1.72 & 56.18 \\
\hline Árvore 11 & & & & & & \\
Raio 1 & 1.04 & 0.67 & 0.35 & 4.25 & 1.15 & 109.96 \\
Raio 2 & 2.41 & 2.20 & 1.06 & 4.08 & 0.94 & 38.86 \\
Raio 3 & 0.59 & 0.59 & 0.40 & 0.77 & 0.14 & 23.11 \\
Raio 4 & 0.43 & 0.42 & 0.25 & 0.71 & 0.12 & 28.44 \\
Média Geral & 1.12 & 0.97 & 0.52 & 2.45 & 0.59 & 50.09 \\
\hline Fonte: (Garcia- comunicação pessoal). & & & &
\end{tabular}

\subsection{Análise da média das espessuras dos anéis das árvores por quinquênio}

Nesta etapa, procedeu-se a análise de regressão para as seis décadas, por quinquênio, onde se estabeleceu entre os modelos pesquisados, aquele que melhor representou a espessura dos anéis de crescimento médios das árvores analisadas, o que permitiu analisar o crescimento dos anéis. As informações sobre a espessura dos anéis de crescimento, permitiram a elaboração das Figuras 3 a 6, além do ajuste dos modelos apresentados na Tabela 7. Nas referidas figuras apresentam-se as séries com a espessura total (lenhos de início e fim de estação) dos anéis de crescimento para cada uma das onze amostras de árvore, nas quais se pode observar a variabilidade das medidas, que pode ser explicada pelos fatores ambientais que de certa forma agiram neste quinquênio e resultaram na formação da espessura dos anéis de crescimento.

Destaca-se também o fato de as árvores serem antigas, e o crescimento rápido ocorrer até a fase adulta, com isso, o desenvolvimento começou a ficar um pouco mais lento após esta fase quando a espessura dos anéis começa a ficar menor. Dessa forma, não foi possível encontrar uma estabilidade no crescimento durante as seis décadas 
analisadas. Na Figura 3 são apresentadas a evolução das médias da espessura dos anéis de crescimento das árvores 1, 2 e 3, onde a árvore 2 se destaca pelo comportamento um pouco diferente das demais, por apresentar, desde a primeira década até 1964, um decrescimento nas suas espessuras. Entretanto, a partir deste ano, ela começou a ter um pequeno acréscimo até o ano de 1984, quando suas espessuras crescem e se mantém constante até o ano de 1994, onde decresce até 2009. A árvore 1 e a 3 apresentaram um desenvolvimento semelhante entre si, no decorrer dos anos, com uma pequena diferença em 2004, quando a média da espessura dos anéis de crescimento da árvore 1 decresce.

Observa-se na Figura 3 o desenvolvimento das árvores 1, 2 e 3, com variações de espessura diferentes para as três. A árvore 1 se manteve com espessura variando de 0,50 a 3,00 mm ao longo dos anos, a árvore 2, manteve um crescimento com espessuras variando de 0,50 a 4,00mm e, a árvore 3, manteve um crescimento com espessuras de 0,50 a 3,00 $\mathrm{mm}$ ao longo dos anos.

Figura 3 - Média, por quinquênio, da espessura dos anéis de crescimento das árvores 1, 2 e 3 do município de Tapera - RS.

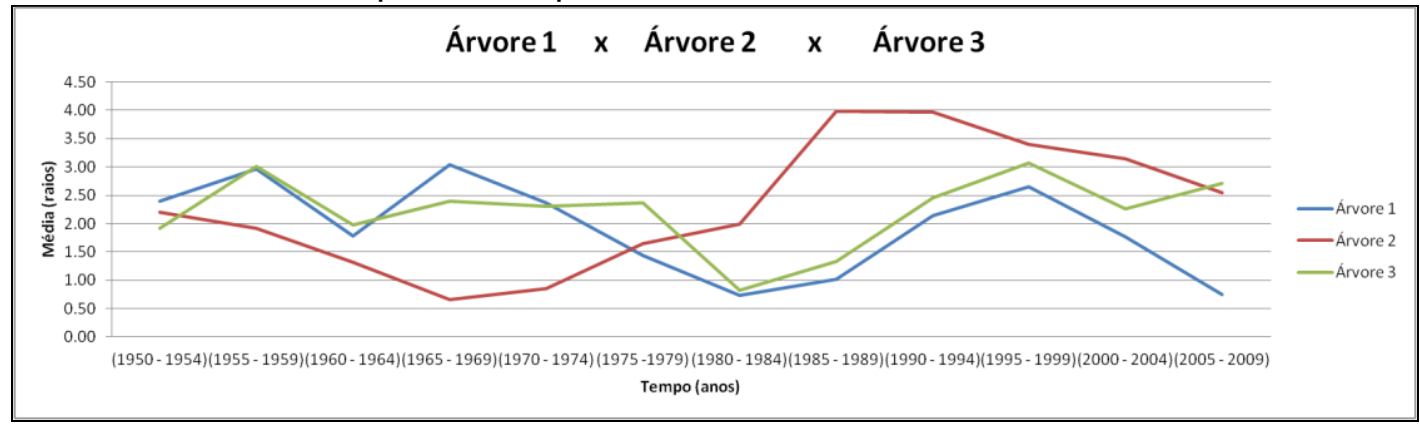

Na Figura 4 apresenta-se o desenvolvimento das árvores 4, 5 e 6, com variações de espessura diferentes para as três. A árvore 4 se manteve com espessura variando de 1,00 a 3,50 mm ao longo dos anos, a árvore 5, manteve um crescimento com espessuras variando de 0,50 a 2,50mm e, a árvore 6, manteve um crescimento com espessuras de 2,00 a 4,00 mm. Observa-se que as árvores 4, 5 e 6 começam com espessuras que vão diminuindo até o ano de 1954, a partir deste ano cada uma apresentou um desenvolvimento diferente. 
Figura 4 - Média, por quinquênio, da espessura dos anéis de crescimento das árvores 4, 5 e 6 do município de Tapera - RS.

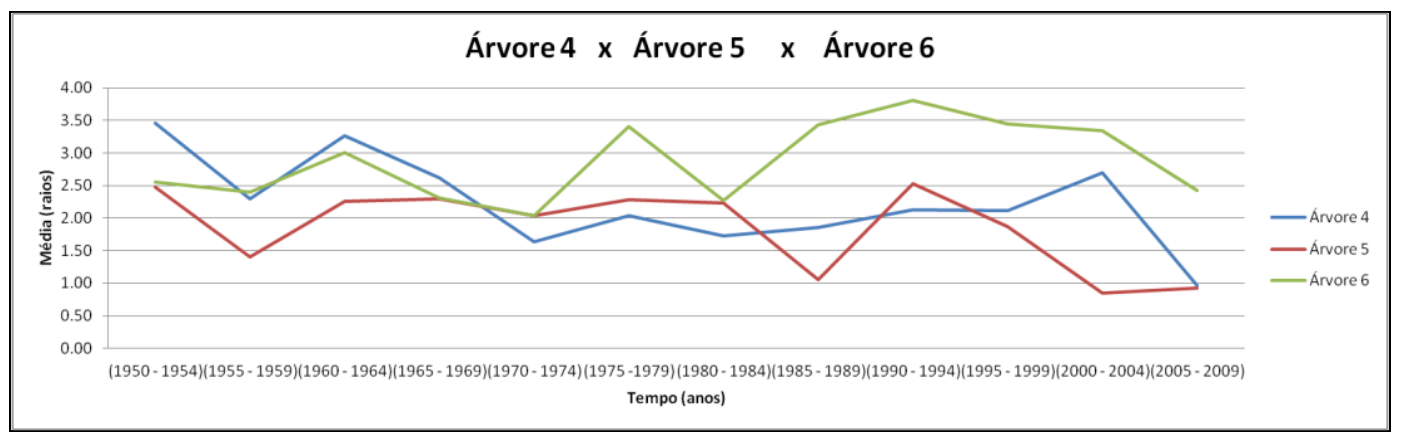

Na Figura 5 apresenta-se o desenvolvimento das árvores 7, 8 e 9, com variações de espessura diferentes para as três. A árvore 7 se manteve com espessura variando de 1,00 a 3,50 $\mathrm{mm}$ ao longo dos anos, a árvore 8, manteve um crescimento com espessuras variando de 0,50 a 4,00mm e, a árvore 9, manteve um crescimento com espessuras de 0,50 a 3,00 mm. Pode-se observar que as árvores 7, 8 e 9 começam com desenvolvimentos de crescimento até o ano 1954. A árvore 9 a partir de 1960 cresceu até 1984 quando começou a decrescer até 1990 e se manteve com uma variação pequena até 2009.

Figura 5 - Média, por quinquênio, da espessura dos anéis de crescimento das árvores 7, 8 e 9 do município de Tapera - RS.

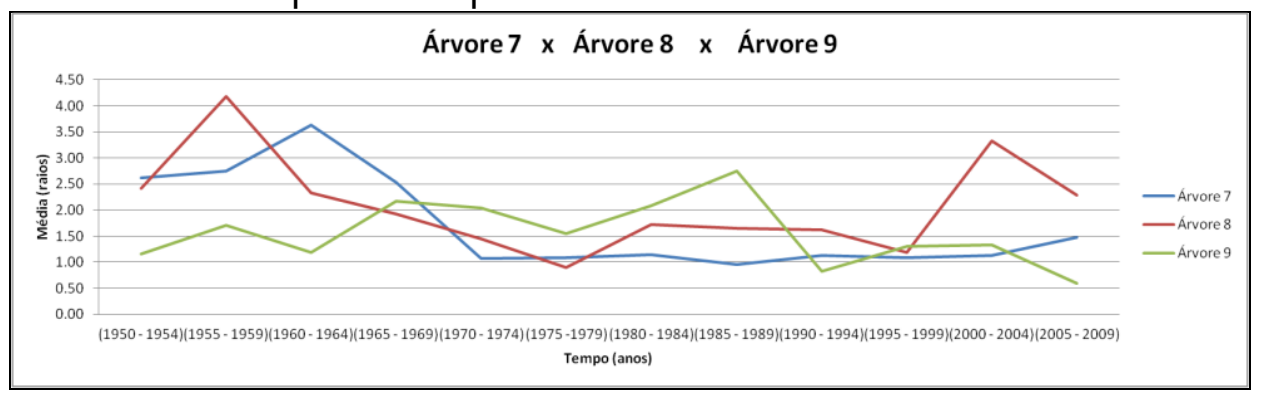

Na Figura 6 apresenta-se o desenvolvimento das árvores 10 e 11, com variações de espessura diferentes para as duas. A árvore 10 se manteve com espessura variando de 1,50 a 4,00 $\mathrm{mm}$ ao longo dos anos e, a árvore 11, manteve um crescimento com espessuras variando de 0,50 a $1,0 \mathrm{~mm}$. 
Figura 6 - Média, por quinquênio, da espessura dos anéis de crescimento das árvores 10 e 11 do município de Tapera - RS.

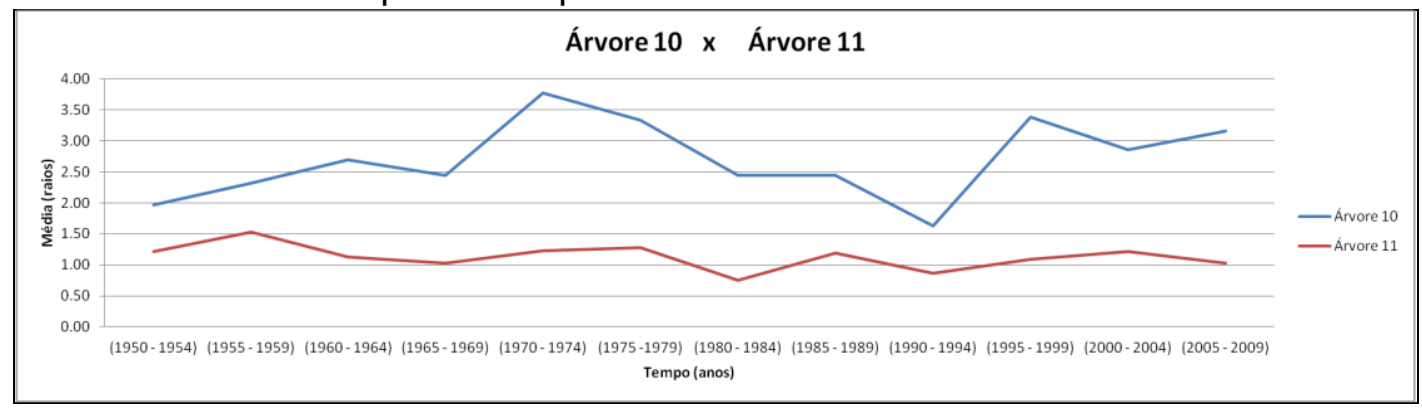

Na Tabela 7 apresentam-se os principais resultados dos ajustes das equações de regressão, considerando-se quatro tipos de funções: a linear, a inversa, a cúbica e a compound.

Tabela 7 - Modelos das médias dos anéis de crescimento de cada árvore do município de Tapera - RS.

\begin{tabular}{|c|c|c|c|c|}
\hline Árvore & Função & Equação & $\mathrm{R}^{2}$ ajustado & AIC \\
\hline $\mathrm{A} 1$ & Linear & $\begin{array}{cc} & \widehat{Y}=1,920-0,50 t \\
(p<0,001) \quad(p=0,098)\end{array}$ & 0,175 & $-5,505$ \\
\hline A2 & Cúbica & \begin{tabular}{c}
\multicolumn{4}{c}{$=2,163+0,346 t+0,003 t^{2}-0,003 t^{3}$} \\
$(p<0,001) \quad(p=0,430) \quad(p=0,001) \quad(p<0,001)$ \\
\end{tabular} & 0,795 & $-12,979$ \\
\hline A3 & Inversa & $\begin{array}{ll} & \widehat{Y}=2,218-\frac{1}{t} \\
(p<0,001) \quad(p=0,084)\end{array}$ & 0,196 & $-11,290$ \\
\hline A4 & Linear & $\begin{array}{c}\widehat{Y}=2,231-0,059 t \\
(p<0,001) \quad(p=0,033)\end{array}$ & 0,317 & $-11,423$ \\
\hline A5 & Linear & $\begin{array}{c}\widehat{Y}=1,850-0,047 t \\
(p<0,001) \quad(p=0,069)\end{array}$ & 0,223 & $-12,568$ \\
\hline A6 & Cúbica & $\begin{array}{cll} & \widehat{Y} & =2,983+0,136 t-0,002 t^{2}-0,001 t^{3} \\
p<0,001) & (p=0,037) & (p=0,510) \quad(p=0,082)\end{array}$ & 0,282 & $-13,176$ \\
\hline A7 & Cúbica & $\begin{array}{c}\widehat{Y}=1,335-0,170 t+0,008 t^{2}+0,001 t^{3} \\
(p<0,001) \quad(p=0,018) \quad(p=0,060) \quad(p=0,172)\end{array}$ & 0,651 & $-11,855$ \\
\hline A8 & Compound & $\begin{array}{cc}\widehat{Y}=1,917 \cdot 0,988^{t} \\
(p<0,001) & (p<0,001)\end{array}$ & $-0,50$ & $-18,148$ \\
\hline A9 & Compound & $\begin{array}{c}\widehat{Y}=1,439.0,978^{t} \\
(p<0,001) \quad(p<0,001)\end{array}$ & 0,051 & $-18,866$ \\
\hline A10 & Compound & $\begin{array}{c}\widehat{Y}=2,636.1,009^{t} \\
(p<0,001) \quad(p<0,001)\end{array}$ & $-0,024$ & $-32,110$ \\
\hline A11 & Compound & $\begin{array}{c}\widehat{Y}=1,112.0,990^{t} \\
(p<0,001) \quad(p<0,001)\end{array}$ & 0,063 & $-39,380$ \\
\hline
\end{tabular}

Fonte: (Garcia- comunicação pessoal).

Considerando-se a análise de resíduos observou-se, para todos os modelos ajustados: média zero, variância constante (homocedasticidade), normalidade e ausência de outlier. Quanto à autocorrelação dos resíduos, a maioria mostrou-se descorrelacionada, com exceção das árvores A6 e A7, cujos resultados se mostraram inconclusivos. 


\section{CONCLUSÃO}

Esta pesquisa teve por objetivo analisar, no município de Tapera no RS, os incrementos dos anéis de crescimento de araucárias nas últimas seis décadas e avaliar os resultados obtidos com o intuito de encontrar um modelo de regressão apropriado para descrever este comportamento, considerando que outros estudos abordaram análises distintas, como enfoque nas variações químicas, radiação solar, e comparação com outras espécies, entre outras. Conhecer a dendrocronologia e outros aspectos sobre os anéis de crescimento permitiu concluir que é um campo novo de pesquisa e complexo, com muitas técnicas disponíveis.

No desenvolvimento deste trabalho, ao analisar o crescimento da espécie, nas últimas décadas no município de Tapera no RS, observou-se que, no decorrer dos quinquênios as espessuras dos anéis variavam de 0,50 a 4,00 mm. Ao avaliar os resultados obtidos com o intuito de encontrar um modelo de regressão apropriado para descrever o crescimento dos anéis das árvores do município de Tapera no RS, os modelos identificados foram: linear, cúbica, inversa e compound. Entretanto, para algumas árvores, os modelos ajustados não foram muito eficientes. Assim, esta pesquisa pode contribuir para ampliar o conhecimento da evolução do desenvolvimento dos anéis desta espécie de araucária, nas décadas consideradas, servindo de referência para estudos similares, considerando que, para esta base de dados, não foram realizadas análises similares.

\section{AGRADECIMENTOS}

Agradecimentos ao INPE/CRS (Instituto Nacional de Pesquisas Espaciais/Centro Regional Sul), pelo espaço utilizado no laboratório, pelos dados fornecidos através do professor Nivaor (In Memoriam) colaboradores e agências de fomento. Destaca-se que este artigo é oriundo de uma Monografia desenvolvida em 2015. 


\section{REFERÊNCIAS}

BOTOSSO PC, MATTOS PP. Conhecer a idade das árvores: importância e aplicação. Colombo: Embrapa Florestas; 2002; 25p. il.: (Documento, 75).

BURGER LM, RICHTER HG. Anatomia da Madeira. São Paulo: Nobel; 1991.

CARVALHO PER. Espécies arbóreas brasileiras. Brasília: Embrapa Informação Tecnológica; 2003.

FONSECA JS da, MARTINS G A, TOLEDO GL. Estatística Aplicada. São Paulo: Atlas; 1985.

GIL A C. Como Elaborar Projetos de Pesquisa. 4ª ed. São Paulo: Ed. Atlas; 2009.

GONÇALVES GV. Dendrocronologia no Alto de S. Bento, em Évora: curva de calibração para datações no âmbito da arqueologia. In: Boletim Cultural "A Cidade de Évora”, n. 7; 2007-2008. 19 p.

GUJARATI DN. Econometria Básica. São Paulo: Pearson Makron Books; 2000.

HILL RC, GRIFFITHS WE, JUDGE GG. Econometria. São Paulo: Saraiva; 2006.

JACOBI LF, SOUZA AM, PEREIRA JES. Gráfico de controle de regressão aplicado na monitoração de processos. Revista Produção; 2002; Volume (12): páginas 46-59.

LAUW AMRF. Estudo de anéis anuais de crescimento de árvores como indicadores climáticos em Portugal. [dissertation] (Mestre em Engenharia Florestal e dos Recursos Naturais) - Instituto Superior de Agronomia/ Universidade Técnica de Lisboa, Lisboa; 2011. 150p.

MORENO JA. Clima do Rio Grande do Sul. Porto Alegre: Secretaria da Agricultura, RS; 1961.

PRESTES A. Relação Sol-Terra estudada através de anéis de crescimento de coníferas do holoceno recente e do triássico. [thesis ](Doutorado em Geofísica Espacial) - Instituto Nacional de Pesquisas Espaciais, São José dos Campos; 2006. 142 p.

RIGOZO NR, PRESTES A, NORDEMAN DJ, SILVA HE, ECHER MOS, ERCHER E. Solar maximum epochim prints in tree ring width from Passo Fundo. Brazil (1741-2004); 2008. 
WERKEMA MCC, AGUIAR S. Análise de Regressão: como entender o relacionamento entre as variáveis de um processo. Belo Horizonte, MG: Fundação Christiano Ottoni, Escola de Engenharia da UFMG; 1996. 